\title{
EL ATRACTIVO POR LA INMOVILIDAD RESIDENCIAL ENTRE LA JUVENTUD. EL CASO DE GALICIA
}

\author{
THE ATTRACTION OF RESIDENTIAL \\ INMOBILITY AMONG YOUNG PEOPLE. THE GALICIAN CASE
}

\section{MANUEL GARCÍA DOCAMPO y EDUARDO TERRÉN LALANA} Universidad de la Coruña

Universidad de Salamanca

\author{
PALABRAS CLAVE ADICIONALES ADDITIONAL KEYWORDS \\ Movilidad geográfica, Motilidad, Migraciones, · Residential Mobility, Motility, Migrations, \\ Sociología de la Juventud, Globalización. Sociology of Youth, Globalization.
}

\begin{abstract}
RESUMEN. En una sociedad caracterizada por la globalización y flexibilización de los mercados, por la expansión y creciente accesibilidad de las formas de transporte y comunicación, y por las políticas y modas que hacen de la movilidad un valor, la renuencia de los individuos a la movilidad residencial puede parecer un fenómeno paradójico. Pero, tal y como se refleja en diversos informes y estudios revisados en este trabajo, el atractivo de la inmovilidad parece un hecho persistente en la mayoría de los paises europeos (y especialmente en los del sur). Nuestra investigación aporta datos que confirman esta apreciación para el caso de los jóvenes, cuya supuesta asociación con la movilidad es resultado de una proyección precipitada y determinista sobre los comportamientos esperados del innegable incremento de las posibilidades objetivas de movilidad propiciadas por la extensión de la red de trasportes e información. Junto a este entorno objetivo de la movilidad, sin embargo, parecen existir ciertos factores subjetivos que constituyen su entorno motivacional y que actúan en sentido contrario a las expectativas y posibilidades mencionadas. Su estudio es precisamente lo que busca una sociología de la movilidad hecha desde el punto de vista del actor.
\end{abstract}

ABSTRACT. Within a context defined by globalized and flexible markets, by the increasing access to diverse forms of transport and communication, and by policies and fashions making mobility a value, people's reluctancy to move seems paradoxical. But, as various researches revised in this paper suggest, inmobility remains atractive in most European countries (specially in the South). Our research offers data confirming this hypothesis for the case of young people. Therefore, visions of globalization which project objective speed potentials to people's behaviour seem to be too deterministic and irreflective. Although transportation and telecommunication are generating many new and faster forms of mobility, a distinction is to be made between this speed potentials and their use. As far as use is preceded by motivation, a deeper exploration of subjective factors underlying this motivation is the aim of a sociology of mobility from the point of view of the actor.

E-mail: docampo@udc.es et@usal.es

Revista Internacional de Sociología (RIS)

Tercera Época, No 42, Septiembre-Diciembre, 2005, pp. 151-178 


\section{INTRODUCCIÓN}

La movilidad de las poblaciones humanas es un fenómeno universal que, no obstante, caracteriza especialmente a la sociedad moderna (Lash y Urry, 1998) y ha cobrado una intensidad sin precedentes desde las últimas décadas del siglo XX, a medida que se han ido generalizando las mejoras tecnológicas en la difusión de personas, mercancías e información. La movilidad se ha difundido, de hecho, como valor de una nueva época. "Más lejos, más deprisa" - como sintetiza John Urry (1999), uno de los principales teorizadores del fenómeno- parece ser el lema: las visiones de un mundo sin fronteras y de poblaciones viajeras forman parte del imaginario colectivo impulsado por muchos dibujos precipitados, superficiales o comerciales de la globalización. La investigación que aquí presentamos parte del convencimiento de que, efectivamente, la movilidad geográfica es un fenómeno saliente del actual cambio social y de que constituye, por tanto, uno de los campos de aplícación sociológica que más fruto puede dar en la teorización del nuevo estadio de sociedad a que nos enfrentamos en los comienzos de este siglo XXI. Pero defendemos igualmente que una teoría de la movilidad sociológicamente potente no puede derivarse simplemente de las oportunidades estructurales que ofrece un conglomerado tecnológico como el de la sociedad globalizada, sino que debe dar cabida a la perspectiva del actor y, más concretamente, a la de su predisposición a la movilidad. En ello radica precisamente nuestra aportación.

Es importante señalar que la actualidad de este campo de estudio no radica sólo en su interés científico ${ }^{1}$. La progresiva globalización de las economías a lo largo de las últimas décadas, y las crecientes exigencias de flexibilidad y movilidad tanto de las mercancías y los capitales como de los individuos, han generado también un progresivo interés político en el análisis de la distribución espacial de las poblaciones y en los procesos tanto estructurales como culturales que los condicionan. Especialmente en Europa, los nuevos contextos de regulación legal de la movilidad internacional y las políticas que tienden a favorecerla contribuyen a una expectativa generalizada de creciente movilidad. No obstante, parece que la movilidad real se produce, $\mathrm{y}$ - lo que aquí más nos interesa - incluso se desea, mucho menos de lo esperado, y ello se refleja en numerosos foros y declaraciones políticas que manifiestan una profunda preocupación por la escasa movilidad geográfica de los trabajadores europeos.

\footnotetext{
'Además de la obra del ya mencionado J. Urry, son igualmente significativos del interés sociológico que tiene el estudio de la movilidad el monográfico de Les Annales de la Recherche Urbaine, 59-60 (1993), Orfeuil (1994) o Viart (1994). En el ámbito de la sociología española, véase Bericat (1994).
} 
De ahí que, si bien parece claro que no puede establecerse de antemano cuál es el nivel de movilidad deseable para una población, ni pueden compararse sin más registros de movilidad de naturaleza diversa, lo cierto es que la constatación de la escasa movilidad residencial de los europeos (sobre todo, de los del Sur) forma parte de la batería de problemas abordada por muchos informes y grupos de trabajo que han llamado la atención sobre la merma de la empleabilidad y los desequilibrios en la provisión de empleos que se derivan del hecho de contar con una fuerza de trabajo poco flexible debido a su escasa movilidad. En comparación con los Estados Unidos, por ejemplo, el nivel de movilidad residencial en Europa tiende a considerarse como bajo, pues es seis veces menor tanto en lo que respecta a la movilidad interregional como a la interestatal, y lo mismo puede decirse prácticamente respecto a otros países como Australia o Canadá2. En la UE, pese a contar con mayores obstáculos legales en sus movimientos, son más los trabajadores extranjeros no comunitarios que los trabajadores extranjeros procedentes de países de la Unión (Tassinopoulos y Kristenen, 1998). Los países noreuropeos, en los que los sistemas de acceso a la vivienda no están tan ligados a la propiedad, como ocurre especialmente en España, registran una movilidad residencial muy superior porque, en términos generales, la propiedad desmotiva el movimiento (Módenes y López Colás, 2004).

Al igual que el resto de los países del sur de Europa, España registra una movilidad residencial que suele considerarse como baja ${ }^{3}$, lo que según Flaquer (1998: 137) responde a diferentes razones: "en el caso de las jóvenes generaciones, al empleo del marido debemos añadir el de la mujer; en el caso de las familias situadas a la mitad del ciclo vital, el de los hijos adultos que están ahorrando para casarse; y, por último, debemos agregar el importante requisito de que la residencia familiar se encuentre lo más cercana posible del domicilio de los abuelos, ya sea

\footnotetext{
${ }^{2}$ Sólo el 0,4\% de la población de la Unión Europea se mueve anualmente de un Estado a otro (mientras que en los EEUU se trasladan de un Estado a otro el 2,4\%), y, aunque con importantes variaciones nacionales, lo mismo puede decirse del nivel anual de movilidad geográfica intraestatal, que en los EEUU llega al 3\% (CEC, 6453/01). Sobre el caso norteamericano y, en especial, sobre el mito del incremento de la movilidad y de su caracterización como fuente de malestar social, debe verse Fischer (2002).

${ }^{3}$ El estudio " ¿Dónde trabajamos?. Contratación y movilidad geográfica de los trabajadores en España", INEM (2004, www.inem.es), señala que el 11,4\% de las contrataciones efectuadas en España durante el año 2002 supusieron trabajar fuera de la provincia de residencia habitual del trabajador y el 7,1\%, significó el desplazamiento entre regiones y que la movilidad puede asociarse a la juventud, ya que el tramo comprendido entre 25 y 34 años registra el $41,5 \%$ de las contrataciones con desplazamiento. También en el Informe España 2005 (Fundación Encuentro, 2005) destaca el tramo de los adultos jóvenes (entre los 20 y los 35 años) como el que registra una mayor movilidad residencial, que es en su mayoria intraprovincial $(60 \%)$, al que habría que unir una buena parte de la interprovincial de corto recorrido entre municipios limítrofes.
} 
RIS

REVISTA INTERNACIONAL DE SOCIOLOGÍA

№ 42, SEPTIEMBRE-DICIEMBRE, 2005

MANUEL GARCÍA DOCAMPO y EDUARDO TERRÉN LALANA

para que hagan de canguros de los niños pequeños, ya sea para poder atenderlos debidamente en su ancianidad". Ni siquiera entre quienes más podría esperarse en principio una mayor disposición a moverse (parados y jóvenes, por ejemplo) parece ser predominante. La EPA muestra que sólo un $20,7 \%$ de los parados (un $18,4 \%$ si son mujeres) aceptarían un empleo que implicara un cambio de residencia. Y otras fuentes oficiales muestran que los jóvenes españoles son los jóvenes europeos que permanecen durante más tiempo en el domicilio familiar ${ }^{4}$, hasta contraer matrimonio en el 70\% de los casos (Leal Maldonado, 1997). Otras investigaciones (Módenes, 2000) han analizado ya la baja movilidad residencial de la juventud urbana y han destacado la influencia que tiene sobre ella el régimen de tenencia de la vivienda, especialmente en los países del sur de Europa ${ }^{5}$. Como se ve, el recurso a los obstáculos estructurales que desmotivan la movilidad es un denominador común de estas investigaciones. Sin embargo, aun sin negar el peso de estos factores, y en coherencia con nuestro propósito de abordar el estudio de la movilidad desde la perspectiva del actor, nuestro trabajo se alinea más bien en el sentido de quienes - como Gaviria Shabba (2002) - constatan la misma resistencia a la movilidad (especialmente de los jóvenes), pero añaden factores de tipo cultural a los condicionantes materiales.

Así pues, frente a la visión de una supuesta gran disposición a la movilidad que se desprende de una superficial concepción de nuestra época (consecuencia, generalmente, de una precipitada concepción de la globalización), y frente al innegable incremento de las posibilidades objetivas de movilidad propiciadas por la extensión de la red de trasportes, parecen existir ciertos factores subjetivos que tienen un enorme peso y que actúan en sentido contrario a las expectativas y posibilidades mencionadas, haciendo atractiva la inmovilidad incluso en el caso de existir una motivación económica para el cambio residencial. No en vano, a la vista de los datos que muestran la inercia hacia la inmovilidad, una delegación especializada de la Unión Europea se ha visto obligada a reconocer la existencia de "una reticencia natural a moverse". Y, sin embargo, como constata la misma fuente $-\mathrm{y}$ aquí es donde radica el interés de nuestra investigación-, aunque se ha especulado mucho sobre la influencia de los factores que inhiben la movilidad, "no existe apenas investigación sobre la actitud del público en general hacia la

\footnotetext{
${ }^{4}$ En España, 9 de cada 10 jóvenes (y 8 de cada 10 jóvenes italianos o portugueses) entre 20 y 24 años siguen en el domicilio familiar, mientras que la media para todos los jóvenes de la antigua Unión Europea (UE-15) es de sólo 6'6 (Eurostat, 1996).

${ }^{5}$ También López Pinto (1999) señala que el mercado laboral español, en los últimos treinta años, ha pasado de una cultura de movilidad geográfica, forzada por las circunstancias, a otra de profunda inmovilidad. "Ahora casi nadie quiere moverse del entorno en el que siempre ha trabajado o estudiado, para buscar empleo en otras zonas. Una de las principales razones entre los jóvenes, es la situación de no encontrar una vivienda acorde con los salarios que se obtienen en su primer empleo".
} 
movilidad" y "es difícil determinar en qué medida cada una de las categorías de obstáculos tiene un efecto restrictivo" (TFSM, 2001: 13, 83, 64). Nuestra investigación pretende precisamente contribuir a suplir este vacío.

\section{PLANTEAMIENTO TEÓRICO Y METODOLÓGICO}

A efectos de claridad conceptual, y como puede fácilmente colegirse de los datos sobre movilidad comparada anteriormente referidos, debe tenerse en cuenta que la motivación a la movilidad que consideramos se refiere a la movilidad residencial, un tipo específico de movilidad geográfica si se entiende ésta como mero desplazamiento entre puntos de un espacio físico o territorio. Dejando a un lado el hecho de que existen muy diversas formas de movilidad (aspecto clave para otro tipo de estudios) (Schuler et al., 1997; García Docampo, 2000: 10-12), y para resaltar la perspectiva de nuestro trabajo, nos interesa aquí subrayar la importancia analítica que adquiere la consideración del punto de vista del actor que decide moverse (o no moverse) en el estudio de este tipo específico de movilidad. Después de todo, el cambio residencial pone más de manifiesto que ningún otro tipo de movimiento espacial que la movilidad no es un proceso inscrito en un espacio meramente físico, sino también social y cultural; que no estamos hablando sólo de puntos en el mapa, sino también de puntos en las biografías. Es lo que Courgeau (1988: 17) caracteriza como un "espacio de vida"; un espacio que engloba, pues, no sólo lugares de residencia o de paso considerados por sí solos, sino, también, un entramado de lugares indisociablemente unido a una red de personas, vivencias, expectativas e identidades. Esta noción del espacio de vida se refiere más a la implantación afectiva o simbólica, que al mero domicilio o residencia, y, como veremos, es la que más se ajusta a la perspectiva de nuestro análisis de la "motilidad" o predisposición a la movilidad residencial, en especial por lo que refiere a las variables subjetivas consideradas (y que más adelante presentaremos).

A la hora de fijar el marco teórico en el que se asienta nuestro interés por la perspectiva del actor en el estudio de la predisposición a la movilidad residencial, es importante apreciar cómo la ceguera ante el actor de muchas investigaciones sobre la movilidad ha sido interpretada por Kaufmann (2002) como el efecto de la primacía del interés por el movimiento sobre el interés por el móvil o, más técnicamente, como la confusión entre movilidad y motilidad. Por "motilidad" $(\text { motility })^{6}$ entiende Kaufman la capacidad de un individuo para ser (realmente) móvil, es decir, su disposición a apropiarse de las posibilidades de movilidad que le ofrece su entorno y hacer uso efectivo de ellas en su actividad: "es la forma

\footnotetext{
${ }^{6} \mathrm{El}$ concepto es usado en biología, por ejemplo, para referirse a la capacidad de movimiento de un animal, una célula o un órgano. En sociología ha sido utilizado también esporádicamente por Bauman (2000).
} 
RIS

por la que un actor se apropia del dominio de lo que es posible en la esfera de la movilidad y lo utiliza para el desarrollo de sus proyectos" (2002: 99).

Nuestro objeto de estudio, la motilidad, hace referencia, por tanto, al potencial de movilidad de un individuo; potencial que tiene que ver, por supuesto, con las condiciones o factores estructurales del medio en que se encuentra (acceso a transportes e información, básicamente), pero también con las aspiraciones personales y el estilo de vida ligados a su capital humano y cultural, pues éstos son los que dotan de significado a las condiciones mencionadas y las convierten en oportunidades de movilidad efectiva. Si lo primero constituye el entorno externo de la movilidad, lo segundo constituye el entorno interno al que llamamos motilidad (la disposición de ánimo a moverse). Si la determinación del primero es fácilmente derivable a partir de una relación de las posibilidades materiales de desplazamiento brindadas por la estructura tecnológica, es decir, por las condiciones del acceso derivadas de la localización en un determinado espacio geográfico, la determinación del entorno interno debe hacerse en función de dos tipos de variables dispuestas en las dos dimensiones que caracterizan a este entorno: una, objetiva (determinada por las variables tradicionalmente consideradas sociodemográficas, como el sexo, la edad, la autoctonía o el nivel de estudios); y otra, subjetiva (determinada por otras variables vinculadas a la construcción cultural de la propia biografia y a la percepción del "espacio de vida" anteriormente descrito, tales como la identificación étnica o nacional, la experiencia migratoria de la familia, el carácter aventurero o el optimismo económico).

Ambas dimensiones han brindado los ejes sobre los que se ha estructurado por bloques el cuestionario en que se basó nuestra encuesta ${ }^{7}$. Como se ve, ambas dimensiones internas proporcionan el sentido en el que las condiciones externas son interpretadas y tienden a ser (o no) utilizadas. Los factores o variables incluidos en ambas dimensiones del entorno interno son los que han de explicar la intensidad y dirección de la motilidad, es decir, la propensión o disposición de los individuos (en nuestro caso, los jóvenes) a cambiar de residencia cuando

\footnotetext{
${ }^{7}$ La encuesta se pasó a una muestra de 799 jóvenes, de entre 16 y 29 años, residentes en Galicia, que representan a los 578.675 jóvenes comprendidos en ese grupo de edad registrados como suma del Padrón Municipal de Habitantes a $1^{\circ}$ de enero del 2002, en cada uno de los municipios de las cuatro provincias gallegas. El procedimiento de muestreo fue polietápico, con estratificación de los municipios por su tamaño -resultando cuatro estratos: municipios de más de 50.000 habitantes; de 10.000 a 49.999; de 5.000 a 9.999 y de menos de 5.000-, con selección aleatoria de conglomerados proporcional al tamaño poblacional del estrato $-\mathrm{y}$ optimizando costes- $\mathrm{y}$ con selección última de los individuos entrevistados basándose en cotas de sexo y edad. El error de muestreo para el caso más desfavorable $(\mathrm{p}=\mathrm{q}=50 \%)$ se establece teóricamente para el conjunto de la comunidad gallega en $1,8 \%$. Acompañamos al procedimiento de un sistema de control de calidad por el contraste con otras variables, como nivel de instrucción y estado civil, obteniéndose márgenes de error incluso inferiores al obtenido teóricamente por la fórmula del muestreo aleatorio. El trabajo de campo fue posible gracias a la financiación de programa PGIDIT de la Xunta de Galicia 2002-2003 (ref. O2PXIA10201AF). Una primera exposición de los resultados se presentó como comunicación al VIII Congreso Nacional de Sociologia (Alicante, 2004).
} 
existe, al menos, - tal y como se planteó en nuestra encuesta- una motivación laboral para hacerlo. La cuestión estriba, entonces, en medir el peso de cada una de ellas para saber si unas u otras llaman más o menos al cambio de residencia y poder ofrecer un perfil de los más predispuestos y de los más resistentes a este tipo de movilidad.

Partimos, pues, de la idea de que la decisión de cambiar de residencia es dependiente de una predisposición que resulta excesivamente limitado interpretar en términos de una decisión económica simple. La base motivacional de la movilidad es compleja, y quizá por ello - tal y como se observa en los estudios anteriormente señalados - la movilidad residencial efectiva se registra menos o de diferente forma a lo esperado. Al estudiar la predisposición de los jóvenes a la movilidad residencial lo que estamos estudiando es, precisamente, cómo se configura esta base motivacional que constituye el entorno interno de la movilidad, para distinguirlo de las condiciones materiales o estructurales que constituirían su entorno externo de la predisposición.

Por último, ¿por qué estudiar este fenómeno en la juventud y por qué en Galicia? Nos hemos centrado en la juventud porque, por tratarse de "la edad de las opciones" (como rezaba el título de un reciente congreso de demografía), parece que esta clase de edad encajaría de lleno en esa visión publicitaria de la globalización que exhibe una población atraída por la movilidad ${ }^{8}$. Después de todo, a ella ha estado especialmente dirigida la pedagogía de la movilidad internacional desarrollada en Europa desde los años $60^{\circ}$. Por otro lado -y más allá de las economías de esfuerzo que limitaron la muestra al ámbito en el que trabajamos-, el estudio de esta predisposición parecía especialmente significativo para el caso de una comunidad como la gallega, tradicionalmente exportadora de emigración y en la que, en consecuencia, los jóvenes están especialmente sensibilizados con los costes y beneficios que implica una experiencia de cambio residencial. Al peso cultural que esta experiencia tenga debe unirse también el hecho de que Galicia es también la región española con mayor grado de autoctonía, pues es donde más personas viven en el municipio en el que nacieron.

${ }^{8}$ TFSM (2001:12) sugiere, de hecho, que una de las razones por las que han disminuido los niveles de movilidad en Europa durante las últimas décadas se debe al envejecimiento de la población trabajadora.

${ }^{9}$ Ver Kristensen (1998) para un recorrido desde el "Programa para el intercambio de jóvenes trabajadores" impulsado por la CE en 1964 hasta los proyectos más recientes como COMETT, SOCRATES o LEONARDO. 


\section{LA PREDISPOSICIÓN GENERAL A LA MOVILIDAD RESIDENCIAL POR EMPLEO}

Centrar el análisis de la predisposición a la movilidad residencial en la motilidad por empleo ayuda a combatir la excesiva vaguedad polisémica que el término "movilidad" ha ido cobrando y centrarla en una dimensión que consideramos especialmente relevante para la población juvenil. La predisposición a la movilidad residencial por empleo expresa la disposición de los jóvenes a aceptar un empleo en un lugar diferente al de su municipio de residencia. Siendo éste, en principio, sólo un tipo específico de movilidad, se considera central y, en esa medida, se considera un indicador fundamental de predisposición a la movilidad en general, por cuanto es la movilidad profesional y social la que principalmente parece alimentar la movilidad geográfica, sobre todo en el caso de los jóvenes (Agustin, 1998) ${ }^{10}$.

La métrica original que proponemos para medir la motilidad o predisposición a la movilidad residencial de los jóvenes por empleo se basa en un indicador (IP) compuesto por las valoraciones ordinales (en una escala de 1 a 5 , de menor a mayor) con respecto a la predisposición a la movilidad laboral en relación a tres destinos diferentes - otro municipio de la misma región, otra región española o al extranjero. ${ }^{11}$ Con este índice suplimos la métrica basada en la simple lectura de los porcentajes de deseabilidad de movilidad laboral en función del destino, empleada en otros estudios, para construir un índice complejo que pondera la movilidad de largo recorrido, al extranjero, de forma más importante que la del simple cambio del lugar de domicilio hacia otro municipio de la misma región. Esto tiene una ventaja evidente, en cuanto permite resumir en un único valor la predisposición global, así como un inconveniente ligado a la ausencia de homogeneidad, o linealidad, en ese deseo.

Empleando este índice global de predisposición (IP), la primera conclusión general sobre la actitud de los jóvenes gallegos, puede extraerse del Gráfico 1.

\footnotetext{
${ }^{10}$ Pese a ello, el trabajo como tal es la tercera en importancia de las razones esgrimidas por los ciudadanos europeos que cambiaron al menos una vez de residencia en los últimos diez años. Lo fue para un $15 \%$ de ellos, por detrás del $54 \%$ que lo hicieron por razones personales o familiares (54\%) o por motivos relacionados con la vivienda (Eurobarómetro 54.2, 2001).

$" \mathrm{El}$ índice construido pondera con un peso tres veces superior los valores de disposición a cambiar de pais, dos veces superior los valores de cambio de región y deja inalterados los valores unitarios de la disposición a cambiar de municipio dentro de Galicia. El indicador fue finalmente estandarizado en una escala de 0 a 100 , con objeto de hacerlo más intuitivo. La disposición a cambiar de municipio correlaciona fundamentalmente con la de cambiar de Comunidad Autónoma $(0,67)$ y, ésta, a su vez, con la de cambiar de país $(0,67)$. La lógica de transitividad, por su parte, es débil, y la correlación del cambio de municipio con el cambio de país se queda en un $(0,42)$.
} 
En él es manifiesta un clara asimetría hacia la izquierda - los valores de menor predisposición-, e incluso con una moda en el valor 0; es decir, la situación nominal más frecuente es encontrarnos con una predisposición nula a cambiar de lugar de residencia para encontrar un empleo ${ }^{12}$. La media resultante fue de 40,2 y la mediana, ligeramente inferior, se quedó en 37,5.

Gráfico 1.

Distribución de los efectivos según el valor del indice de predisposición

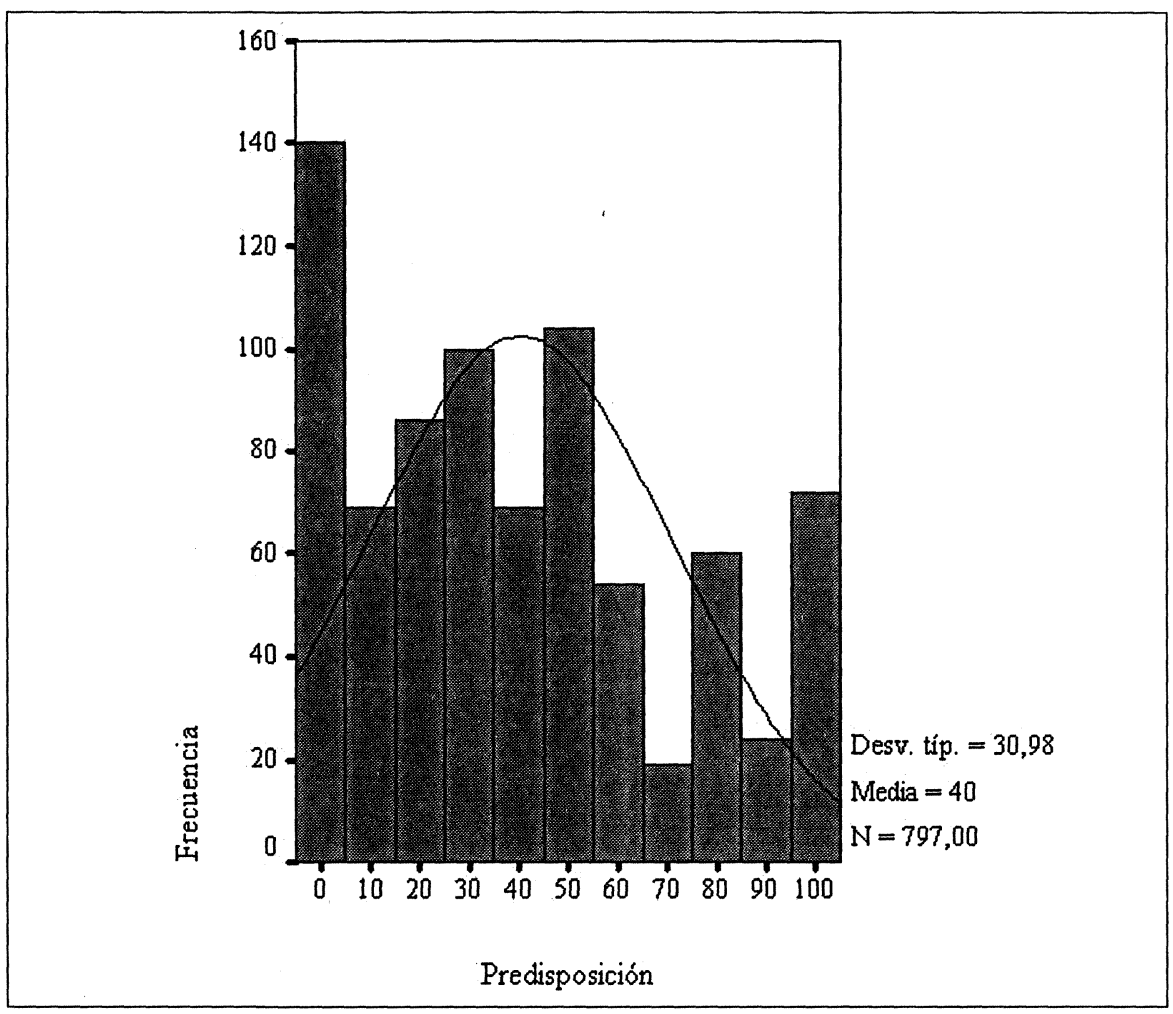

Fuente: Encuesta Movilidad Espacial de la Juventud Gallega, 2003.

${ }^{12}$ Somos conscientes del efecto generado por la mayor ponderación de la predisposición de cambiar el lugar de residencia hacia el extranjero (en casi la mitad de los casos valorada negativamente), frente a los otros destinos. Si modificamos los factores de ponderación el resultado varía considerablemente. No obstante, entre las diferentes variantes ensayadas, hemos optado por ésta, por considerar que permite detectar mejor las características objetivas y subjetivas de la población entrevistada, eje central de nuestras hipótesis. 
RIS

\section{DISTRIBUCIÓN DE LOS EFECTIVOS SEGÚN EL VALOR DEL ÍNDICE DE PREDISPOSICIÓN}

En comparación con la valoración que obtienen medidas similares en otros estudios o informes, y que suelen calificarse como "bajas", cabe inferir de lo expuesto que, en términos generales, la disposición a la movilidad residencial por empleo es también baja entre la juventud gallega. Si la medimos mediante la escala de 5 grados para cada una de las posibilidades contempladas (según el alcance geográfico del cambio propuesto), obtenemos que el valor medio de dicho índice para el caso de los jóvenes gallegos $(40,2)$ los sitúa como promedio en el intervalo categorizado como solamente "algo dispuestos"13.

En relación con la distancia del cambio propuesto, nuestra encuesta mostró también que, como era de esperar, la distancia y la motilidad crecen en sentido contrario. Tal como puede comprobarse en el Gráfico 2, la mayor predisposición se registra hacia destinos en otro municipio gallego (obsérvense, por ejemplo, los porcentajes alcanzados en los ejes de mucha o bastante predisposición). Seguidamente, por este orden, los valores porcentuales más elevados corresponden a los destinos en otra Comunidad Autónoma y al extranjero. Inversamente, en el eje de la nula predisposición (en el gráfico 1 representado como "nada"), la proporción más importante se refiere a los destinos hacia el extranjero y se reduce secuencialmente para cambios hacia otra Comunidad Autónoma y hacia otro municipio gallego.

El 45,9\% de los jóvenes gallegos no está dispuesto en absoluto a aceptar una oferta de trabajo fuera de España, mientras que la resistencia a aceptar esa oferta en otro municipio de la misma región se encuentra sólo en el 13,4\%. Por el contrario, algo más de la mitad de ellos (57\%) están bastante o muy dispuestos a aceptar esta oferta geográficamente cercana, mientras que escasamente una cuarta parte $(22,9 \%)$ estaría tan dispuesto a aceptarla en el extranjero (y sólo en este grupo se aprecia una ligeramente mayor disposición de los jóvenes varones). El ánimo a trasladarse disminuye, pues, claramente, con la distancia del traslado ${ }^{14}$.

\footnotetext{
${ }^{13}$ Empleamos aquí esta recodificación de los valores ordinales obtenidos en el índice de predisposición para hacerla comparativa con la utilizada en otros informes (v. g., Pérez Díaz y Rodríguez, 1998). Consideramos "muy dispuestos" a los individuos que alcanzan una puntuación entre 100 y 75,01 , "bastante dispuestos" a los que obtienen entre 75 y 50,01, "algo dispuestos" a los que están entre 50 y 25,01 , "muy poco dispuestos" a los puntúan entre 25 y 0,01 y "nada dispuestos" a los que puntúan 0 . Con nuestros datos no llega a la tercera parte de los encuestados $(31,8 \%)$ los que pueden considerarse como bastante o muy dispuestos a este tipo de movilidad, resultado ligeramente superior al encontrado por Pérez Díaz y Rodríguez, que califican de "más inclinados a la movilidad" sólo a un $26 \%$ de los jóvenes encuestados por ellos.

${ }^{14}$ Un examen más detallado de la lógica de la predisposición basada en la distancia del destino revela, no obstante, una mayor complejidad. Así, de entre los que cambiarían su domicilio a un lugar del extranjero, no tienen por qué haber respondido que lo cambiarían a otra región o a otro municipio.
} 
Gráfico 2.

Disposición a aceptar un empleo en un municipio distinto del de residencia (Valores porcentuales para cada tipo de destino)

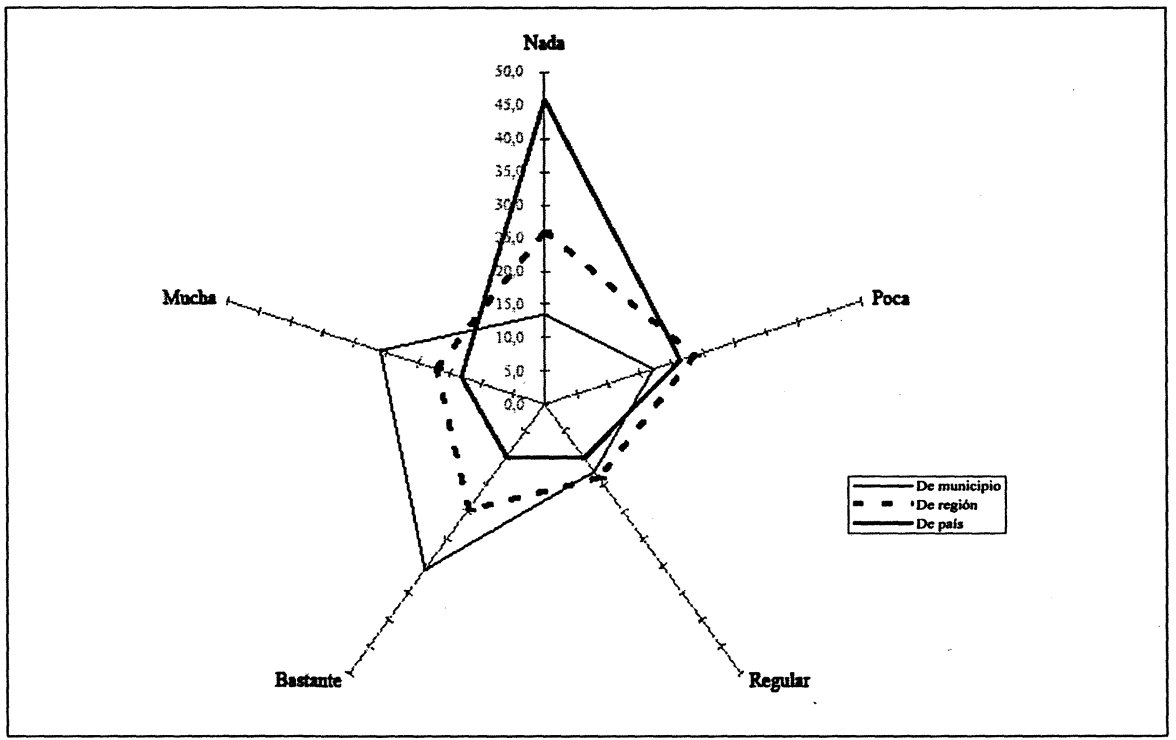

Fuente: Encuesta Movilidad Espacial de la Juventud Gallega, 2003.

\section{FACTORES QUE INFLUYEN EN LA MOTILIDAD}

Tal y como comentamos anteriormente, interesa en este trabajo calibrar la relevancia de diversos factores del entorno interno de la acción que, más allá de la presencia de factores externos, puedan explicar esta baja motilidad o escasa disposición a la movilidad geográfica de la juventud gallega. Tal y como anteriormente dijimos, hemos encuadrado un conjunto de dichos factores en la dimensión interno-objetiva de la motilidad (la que identifica la posición de cada individuo en la estructura social) y otros en la dimensión interno-subjetiva (la relacionada con su estructura de expectativas, identificaciones, experiencias y percepciones).

Los coeficientes de correlación entre esos tres destinos no superan el valor del 0,66 y subyace en esa predisposición una cierta valoración, de una parte de los jóvenes gallegos, a los desplazamientos próximos hacia cualquiera de los municipios gallegos, frente a los que prefieren alguna caracteristica específica del municipio de destino, sea éste en Galicia, en otra región o en el extranjero. En concreto, la variable rural-urbano $u$ otras de similar indole, indicativas de ciertas cualidades del lugar de destino, aparecen como discriminantes en esa predisposición. Por ejemplo, cambiarían el lugar de residencia hacia cualquier ciudad española importante, pero no hacia un municipio rural gallego. 
RIS

REVISTA INTERNACIONAL DE SOCIOLOGIA

\section{Factores objetivos}

Las variables objetivas consideradas se recogen en la Tabla 1. Se observa con facilidad que, en consonancia con lo encontrado por otros estudios (IVIE, 2004), ni el sexo ni la edad parecen ser variables significativas ${ }^{15}$.

Tabla 1.

Predisposición a la movilidad residencial según diversas variables sociodemográficas

\begin{tabular}{|c|c|c|c|}
\hline & & Índice de predisposición & $\mathrm{N}$ \\
\hline \multirow{2}{*}{ Sexo } & Varón & 40,56 & 407 \\
\hline & Mujer & 39,85 & 390 \\
\hline \multirow{3}{*}{ Grupos de edad } & $16-19$ & 32,91 & 176 \\
\hline & $20-24$ & 42,45 & 304 \\
\hline & $25-29$ & 42,13 & 317 \\
\hline \multirow{4}{*}{ Hábitat } & Urbano & 41,95 & 298 \\
\hline & Semiurbano & 41,65 & 260 \\
\hline & Semirural & 40,10 & 125 \\
\hline & Rural & 32,53 & 114 \\
\hline \multirow{3}{*}{ Nacionalidad } & Española & 40,14 & 783 \\
\hline & Española y otra & 45,24 & 7 \\
\hline & Otra & 43,45 & 7 \\
\hline
\end{tabular}

Fuente: Encuesta de Movilidad Espacial de la Juventud Gallega, 2003.

\footnotetext{
${ }^{15}$ Respecto al primero, baste decir que una disposición media de 40,6 para los varones y una de 39,9 para las mujeres permiten considerar como no significativas las diferencias cuadráticas del test de la $\mathrm{F}$ de Fisher. La variable edad, en el intervalo de años considerado, dista también mucho de poder ser considerada como determinante. El coeficiente de correlación de Pearson entre el índice de disposición y el año de nacimiento es del 0,087. El estudio del INEM (2004) señala, sin embargo, que la movilidad laboral registrada en España es menor en el caso de las mujeres (el 63,7\% de los contratos que suponían cambio de residencia fueron suscritos por hombres) y que decrece significativamente con la edad.
} 
El tamaño del municipio de residencia y la nacionalidad, en cambio, sí establecen diferencias significativas. Por lo que al primero respecta —como se refleja más claramente en el gráfico 3-, cuanto mayor es, más elevada resulta la disposición e, inversamente, en los municipios más pequeños es constatable la existencia de una menor disposición a la movilidad. En cuanto a la nacionalidad de origen, se observa una menor predisposición entre las personas que poseen únicamente la nacionalidad española frente a aquéllas que o bien tienen doble nacionalidad o bien son extranjeros.

La variable que mejor correlaciona con la predisposición a cambiar de residencia por un empleo es el nivel de estudios: cuanto mayor es el nivel de instrucción, mayor es la predisposición a la movilidad, lo que es coherente con lo encontrado en otras investigaciones ${ }^{16}$. Los estudios, no obstante, no son sólo relevantes por

Gráfico 3.

Predisposición a la movilidad por tamaño del municipio de residencia

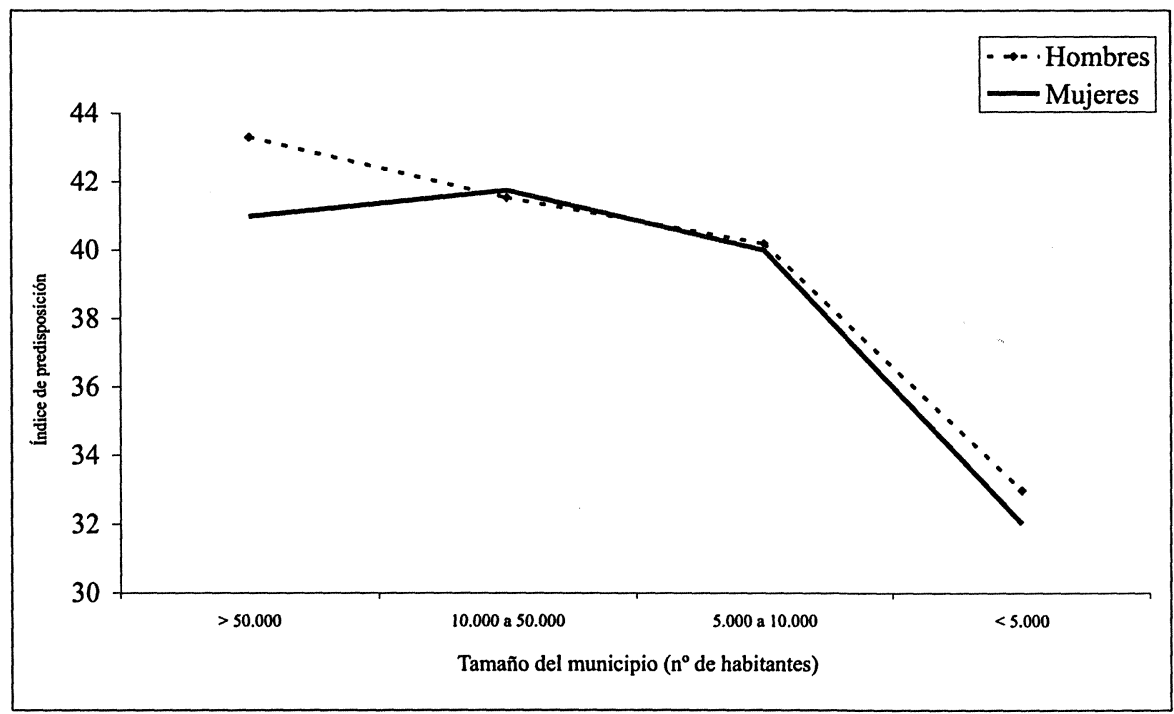

Fuente: Encuesta de Movilidad Espacial de la Juventud Gallega, 2003.

${ }^{16}$ No obstante, el coeficiente de correlación de Pearson arroja una débil capacidad explicativa (un 5,4\% de la varianza explicada por la variable independiente). El estudio de la movilidad geográfica por razones laborales del INEM (2004) considera también que la propensión a la movilidad se incrementa al elevarse el nivel educativo. IVIE (2004), por su parte, encuentra que, aunque sólo un escaso $9 \%$ de los titulados universitarios desearian trabajar en una localidad distinta a la que residen, la proporción es 3 puntos superior a la de los que sólo tienen estudios obligatorios. 
RIS

REVISTA INTERNACIONAL DE SOCIOLOGIA

№ 42, SEPTIEMBRE-DICIEMBRE, 2005

MANUEL GARCÍA DOCAMPO y EDUARDO TERRÉN LALANA

el nivel alcanzado, sino también por el hecho de constituir o no la actividad del joven (Tabla 2). Y es que los estudiantes son mucho más propensos a cambiar de residencia que los activos ${ }^{17}$.

Tabla 2.

Predisposición a la movilidad según nivel de estudios

\begin{tabular}{|c|c|c|c|c|c|c|c|c|c|c|c|c|c|}
\hline & \multicolumn{12}{|c|}{ Grupos de edad } \\
\hline & & \multicolumn{4}{|c|}{$16-19$} & \multicolumn{4}{|c|}{$20-24$} & \multicolumn{4}{|c|}{$25-29$} \\
\hline & & \multicolumn{2}{|c|}{ Varón } & \multicolumn{2}{|c|}{ Mujer } & \multicolumn{2}{|c|}{ Varón } & \multicolumn{2}{|c|}{ Mujer } & \multicolumn{2}{|c|}{ Varón } & \multicolumn{2}{|c|}{ Mujer } \\
\hline & & Índice & $\mathrm{n}$ & Índice & & Índice & $\mathrm{n}$ & Índice & $\mathrm{n}$ & Índice & $\mathrm{n}$ & Índice & $\mathrm{n}$ \\
\hline \multirow{6}{*}{ 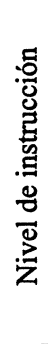 } & Licenciatura & , & & , & & 79,2 & 3 & 66,7 & 15 & 49,4 & 30 & 48,7 & 45 \\
\hline & Diplomatura & , & & 16,7 & 1 & 75,0 & 2 & 54,8 & 7 & 57,2 & 19 & 45,0 & 25 \\
\hline & Bachillerato & 26,1 & 22 & 37,7 & 25 & 37,9 & 60 & 52,8 & 71 & 52,7 & 32 & 37,3 & 34 \\
\hline & FP & 70,8 & 2 & 22,9 & 4 & 38,7 & 48 & 35,4 & 33 & 40,1 & 44 & 31,5 & 39 \\
\hline & Primarios & 36,3 & 70 & 28,6 & 52 & 33,0 & 35 & 27,3 & 24 & 38,9 & 33 & 17,0 & 14 \\
\hline & Sin estudios & , & & , & & 27,1 & 2 & 4,2 & 1 & 0,0 & 1 & , & \\
\hline \multirow{2}{*}{ 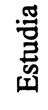 } & SI & 34,1 & 83 & 30,3 & 74 & 45,8 & 68 & 54,4 & 90 & 52,4 & 43 & 50,2 & 46 \\
\hline & NO & 38,6 & 11 & 37,0 & 8 & 33,3 & 85 & 33,7 & 61 & 43,2 & 117 & 33,7 & 111 \\
\hline \multirow{5}{*}{ 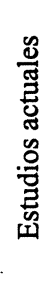 } & Licenciatura & 30,6 & 12 & 31,9 & 12 & 44,8 & 32 & 61,7 & 47 & 55,8 & 18 & 46,0 & 28 \\
\hline & Diplomatura & 27,8 & 3 & 49,3 & 6 & 54,2 & 7 & 52,5 & 23 & 49,1 & 9 & 46,4 & 7 \\
\hline & Bachillerato & 41,9 & 30 & 24,4 & 29 & 46,9 & 8 & 30,4 & 7 & , & & , & \\
\hline & FP & 31,0 & 21 & 39,6 & 14 & 33,6 & 16 & 39,0 & 11 & 44,0 & 7 & 52,1 & 2 \\
\hline & Primarios & 27,7 & 17 & 23,1 & 13 & 78,3 & 5 & 75,0 & 2 & 55,6 & 9 & 65,7 & 9 \\
\hline
\end{tabular}

Fuente: Encuesta de Movilidad Espacial de la Juventud Gallega, 2003.

${ }^{17}$ En cambio, el tipo de estudios que están realizando los estudiantes actuales no muestra, al contrario de lo que pasaba con la variable nivel de instrucción, un comportamiento lineal. En este caso, el valor alcanzado por Licenciados y Diplomados es casi idéntico, frente al de Bachillerato y FP que se reduce en 15 puntos -conservando, además, una clara proximidad entre estas dos categorias de estudios-, para romper la tendencia descendente con el nivel alcanzado por los que realizan estudios primarios, que incrementan el valor hasta situarse sólo 5 puntos por debajo del de los universitarios. 
En relación con la preocupación que, como vimos en la introducción, suscita la escasa motilidad de los parados, un importante factor a considerar era la mayor o menor predisposición a la movilidad de los jóvenes en relación con su actividad económica (Cuadro 1).

Cuadro 1.

Predisposición según relación con la actividad

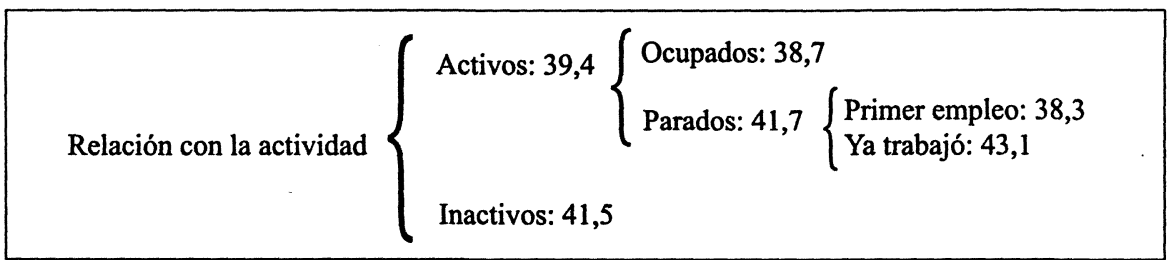

Fuente: Encuesta de Movilidad Espacial de la Juventud Gallega, 2003.

El índice observado controlando la relación que los jóvenes tienen con la actividad económica no aparenta mostrar grandes diferencias, si bien éstas aparecen si desmenuzamos las diferentes categorías que definen dichas situaciones. Así activos e inactivos muestran valores muy próximos; pero, entre los activos, como intuitivamente se esperaba, los que están ocupados muestran una disposición inferior a los parados. Llama la atención, sin embargo, que los jóvenes parados que buscan su primer empleo muestren una predisposición bastante más baja (casi 5 puntos) que los jóvenes parados que ya han trabajado con anterioridad. Por lo que respecta a la empleabilidad de los recién llegados al mercado de trabajo, un resultado importante es que parece que la primera búsqueda de empleo está poco predispuesta a la movilidad. Pero, curiosamente, teniendo en cuenta la duración del periodo de búsqueda (gráfico 4), esta disposición varía de forma inversa en los dos casos: el cansancio que se asocia con la búsqueda anima a la movilidad a los que nunca trabajaron, mientras la desanima en los que ya trabajaron antes.

Cabe señalar que entre los jóvenes ocupados las diferencias en función del tipo de empleo no son muy claras, aunque en términos generales, las ocupaciones más cualificadas y de mayor status reflejan valores de predisposición mayores que las observadas en el resto de los grupos, lo cual es coherente con la mayor predisposición encontrada entre los jóvenes con más estudios (que, es de suponer, ostentan generalmente los empleos más cualificados). No obstante, las diferencias de dicho índice se hacen más patentes, especialmente en determinadas categorías ocupacionales, si las cruzamos con la variable "tiempo que lleva en ese puesto de trabajo". En ese caso, es especialmente clara la diferencia que aparece entre los ocupados en la categoría "cuadros" - aquellos asalariados que para desempeñar sus funciones precisan una titulación universitaria superior. El índice alcanza un valor próximo a 60 para los que llevan menos de un año en el empleo y se reduce paulatinamente según se va estabilizando el mismo, hasta llegar a valores por debajo del nivel 30 en los casos en que lleven más de 3 años en ese empleo. 


\section{RIS}

\section{Gráfico 4.}

Predisposición a la movilidad de los parados según tiempo de buisqueda de empleo

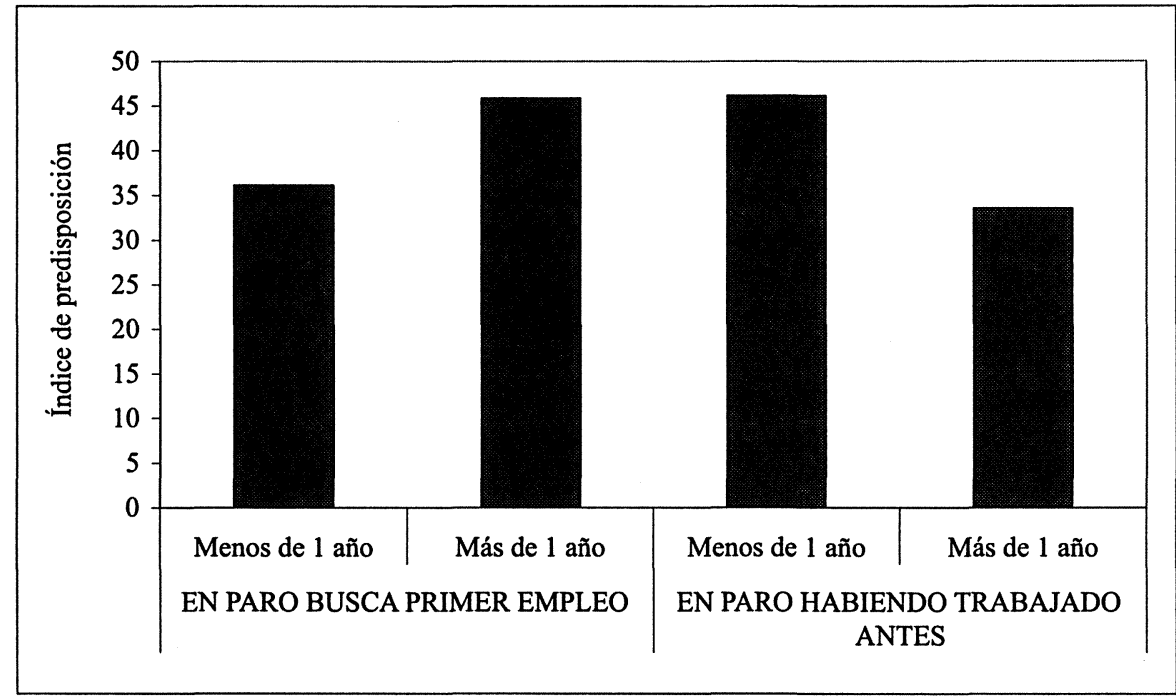

Fuente: Encuesta de Movilidad Espacial de la Juventud Gallega, 2003.

\section{Gráfico 5.}

Predisposición según tiempo en el empleo y categoría ocupacional

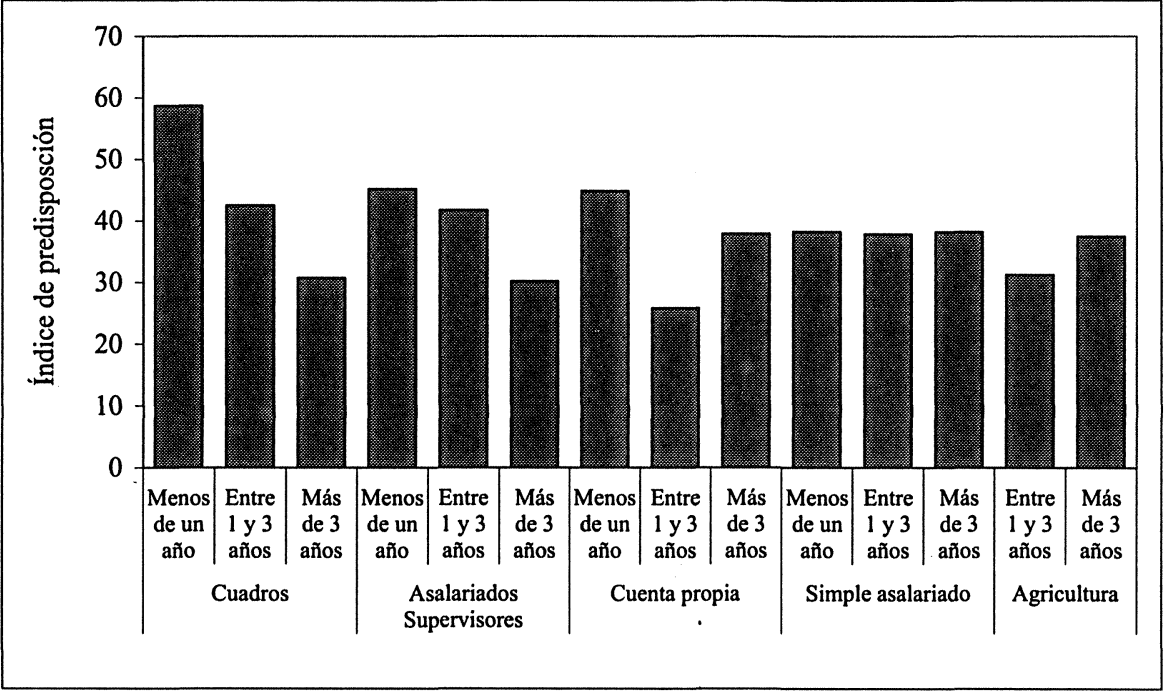

Fuente: Encuesta de Movilidad Espacial de la Juventud Gallega, 2003.

166 
La misma lógica de menor predisposición a mayor estabilidad en el empleo es válida entre los asalariados con tareas de supervisión, si bien en este caso, el rango de valores entre los más inestables —con menos tiempo en el empleo-y los más estables, es menor que en el caso de los cuadros (apenas 10 puntos). Los autónomos ocupados por cuenta propia muestran, a su vez, unos índices de predisposición que parecen seguir otra pauta, aunque dentro de la misma lógica, a saber: los que recientemente han iniciado su actividad profesional como autónomos, junto con los que ya llevan más años con el mismo (estos últimos en menor medida), responden más afirmativamente a la posibilidad de moverse, frente a los que parece que llevan entre 1 y 3 años con su autoempleo en marcha, que parece que esperan mejores resultados o una conclusión de sus inversiones anteriores.

En las categorías ocupacionales inferiores, la lógica de la estabilidad no se mantiene. Entre los simples asalariados, el tiempo en el empleo aparece como una variable claramente espuria. La variable tiempo es independiente de la de predisposición, y los valores que arrojan prácticamente coinciden con los de la media obtenida para el conjunto de jóvenes gallegos. Con ciertos matices, también los agricultores podrían incluirse en esa misma pauta. Entre los ocupados, la variable satisfacción con el trabajo discrimina la predisposición, pero lo hace básicamente sólo en los casos negativos, cuando la satisfacción es nula o poca, con los consiguientes valores más elevados del índice. Por su parte, los niveles de satisfacción medios y positivos no eliminan la predisposición, pero se ubican en torno a los valores medios de la población joven en general.

La existencia de cargas familiares limita claramente la predisposición entre los que tienen hijos o mayores a su cuidado, frente a los que no. El IP varía de 29,6 para los que tienen cargas, frente a un 41,17 de los que carecen de las mismas. Algo similar, aunque no tan acusado, ocurre con los jóvenes que conviven con su pareja y, en la misma línea, la estabilidad que proporciona el vivir de ingresos propios reduce la predisposición ${ }^{18}$.

Dentro de los factores objetivos que pueden influir en la motilidad de los jóvenes merecía especial consideración la autoctonía, pues permitiría ver si el historial de cambio residencial personal o familiar incidía en su mayor o menor predisposición. Sabido es, además, que Galicia es la región española con mayor proporción de personas que viven en el municipio en que nacieron ${ }^{19}$. De hecho, dos terceras partes de los jóvenes encuestados $(66,1 \%)$ han residido siempre en el mismo municipio, proporción similar a la de la población gallega en general, que

\footnotetext{
${ }^{18}$ Para los que conviven con su pareja, el IP alcanzado es de 31,46 , frente al 41,42 de los que no están en esa situación. Por su parte, los que viven de sus ingresos frente a los que no lo hacen muestran valores del 35,37 y 42,40, respectivamente.

${ }^{19}$ El 65\%, según el Anuario Social de España (Fundación La Caixa), lo que coloca a Galicia junto con Murcia como las regiones españolas con mayor índice de autoctonía.
} 
reside en el municipio en que nació. Curiosamente, no parece que la trayectoria residencial tenga un especial impacto sobre dicha disposición, pues su índice de disposición a cambiar de residencia por un buen empleo es sólo muy ligeramente inferior a los que han tenido una biografía de cambio residencial $(39,7$ frente a $41,1)$. No parece, pues, que la movilidad personal pasada llame a una considerable mayor disposición a la movilidad futura.

Sí, en cambio, se muestran muy significativas las condiciones sociales de origen, tanto si las medimos a través de la ocupación del cabeza de familia, como del nivel de estudios del padre y la madre (Tabla 3). A mayor nivel de instrucción alcanzado, siempre hay una mayor predisposición, y lo mismo ocurre con la clase social.

Tabla 3.

Predisposición a la movilidad según estudios y clase social de los padres

\begin{tabular}{|ll|c|}
\hline & & Predisposición \\
\hline \multirow{3}{*}{ Estudios del padre } & Superiores & 45,55 \\
& Medios & 42,65 \\
& Primarios & 37,37 \\
& Sin estudios & 30,48 \\
\hline \multirow{2}{*}{ Estudios de la madre } & Superiores & 53,31 \\
& Medios & 41,67 \\
& Primarios & 37,78 \\
& Sin estudios & 24,52 \\
\hline Clase social del cabeza de & Clase Servicio & 50,14 \\
familia & Asalariados Supervisores & 32,47 \\
& Cuenta propia & 40,06 \\
& Simple Asalariado & 40,56 \\
& Agricultura & 29,02 \\
\hline
\end{tabular}

Fuente: Encuesta de Movilidad Espacial de la Juventud Gallega, 2003.

\section{Factores subjetivos}

En el estudio de las variables que hemos considerado representativas de la dimensión subjetiva de la predisposición a la movilidad, hemos prestado atención a aquellas relacionadas con la vivencia del espacio en que se reside (el espacio de vida señalado en la primera sección) y con lo que a grandes rasgos podríamos describir como "el deseo de cambiar de sitio".

Una de las relaciones más esperadas en este sentido era que los jóvenes más dispuestos a cambiar su residencia en función de una oferta de trabajo fueran 
los que en general muestran un mayor deseo de vivir en un sitio diferente al que viven, es decir, los que muestran lo que denominamos disposición a la movilidad absoluta (sin referencia a una oferta de empleo). Sin diferencias significativas según sexo, una vez más, el $56 \%$ de los jóvenes entrevistados manifestaron esa disposición al afirmar desear vivir en otro sitio en un futuro próximo, que era el indicador utilizado para medir esta variable (Tabla 4).

Tabla 4.

Predisposición asociada al deseo de movilidad absoluta y atracción por la novedad

\begin{tabular}{l|lcc}
\hline \multicolumn{2}{l}{} & $\begin{array}{c}\text { Porcentaje } \\
\text { respuestas }\end{array}$ & $\begin{array}{c}\text { Índice de } \\
\text { predisposición }\end{array}$ \\
\hline \multirow{2}{*}{$\begin{array}{l}\text { Deseo de vivir en otro } \\
\text { lugar }\end{array}$} & Sí & 56,7 & 47,1 \\
& No & 43,0 & 31,3 \\
& No sabe & 0,4 & 22,2 \\
\hline \multirow{4}{*}{$\begin{array}{l}\text { Atracción por los } \\
\text { sitios nuevos y gentes } \\
\text { distintas }\end{array}$} & Prefiere tranquilidad de & 43,3 & 33,5 \\
& sitios conocidos & & \\
& Prefiere novedad de & 54,9 & 45,3 \\
& nuevos sitios & 1 '9 & 42,5 \\
\hline
\end{tabular}

Fuente: Encuesta Movilidad Espacial de la Juventud Gallega, 2003.

El índice de disposición a la movilidad de los que albergan este deseo es muy superior al de los que querrían vivir siempre donde ahora lo hacen $(47,1$ frente a $31,3)$ y, entre ellos, la disposición aumenta a medida que su deseo de vivir en otro sitio se proyecta más lejos (Gráfico 6). Es, así, mayor entre los que les gustaría vivir en el extranjero $(58,7)$ que entre los que desearían vivir en otro lugar de España $(44,1)$ o entre los que querrían vivir simplemente en otro municipio de la misma comunidad autónoma $(33,56)$.

En el mismo sentido de esa disposición a la movilidad absoluta (el deseo de vivir en otro sitio simplemente) parece funcionar otro factor ligado a la personalidad como es el apego a lo ya conocido y habitual (recogido también en la tabla 4). En relación con ello podríamos calificar como más aventurero o emprendedor el carácter propio de quienes consideran más atractivo la novedad de los sitios diferentes y la posibilidad de hacer nuevas amistades, que la tranquilidad de conducirse en los sitios habituales y entre gente conocida. Una exigua mayoría del $55 \%$ de los jóvenes parecen sentirse atraídos por esta primera opción; y ello sí parece tener un cierto influjo sobre la predisposición a la movilidad residencial por empleo, pues, quienes así sienten, muestran una predisposición casi superior en 12 puntos a la de los que prefieren la tranquilidad de lo habitual y ya conocido $(45,3$ frente a 33,5$)$. 
Gráfico 6.

Lugares en que se desearia vivir y predisposición asociada

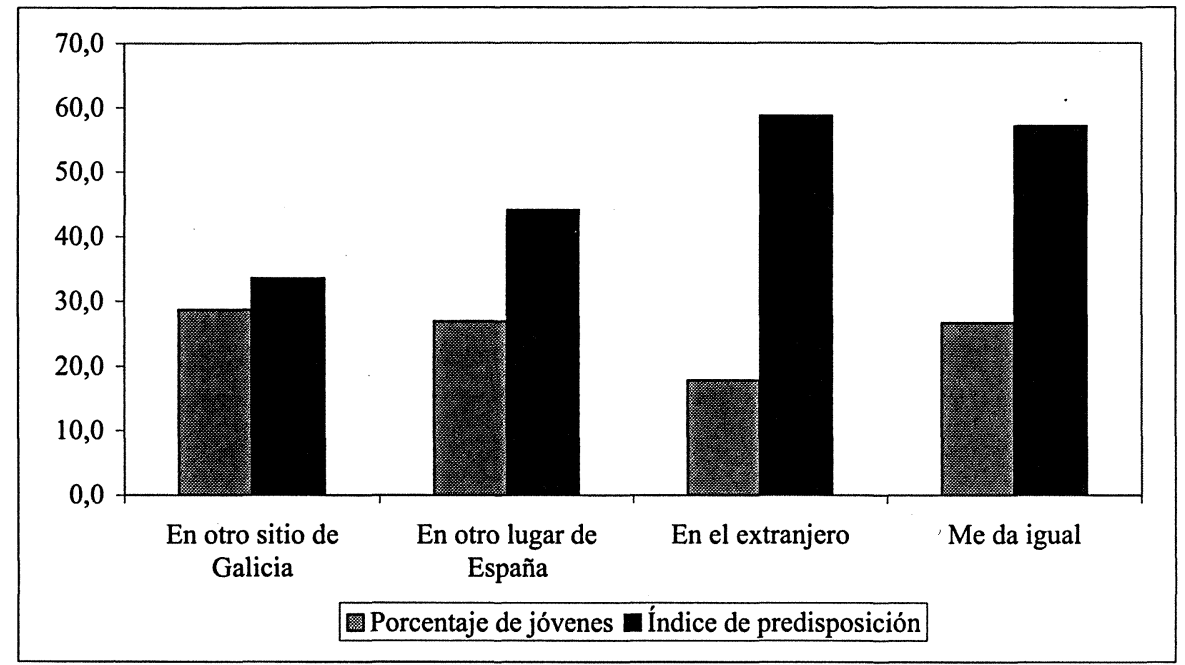

Fuente: Encuesta Movilidad Espacial de la Juventud Gallega, 2003.

Tal y como vimos en la segunda sección, el bajo ánimo a la movilidad de la juventud gallega parecía confirmar para esta población la tesis de la atracción por la inmovilidad, pues sólo una tercera parte se muestra algo dispuesta a ella, y otra tercera parte claramente muy poco dispuesta. Parece corroborar esta apreciación el hecho de que la mitad de los encuestados se muestren muy de acuerdo o de acuerdo con que, siempre que no se pierda demasiado, es preferible cambiar de trabajo que de lugar de residencia, mientras que sólo el 38\% cambiarían de residencia por mantener su trabajo.

Ya vimos en la sección anterior cómo esta resistencia a abandonar el lugar en el que se reside guardaba poca relación con la autoctonía, pues la predisposición a la movilidad de los que siempre han vivido en el mismo municipio y la de los que no, era muy parecida. No obstante, la experiencia biográfica de cambio residencial no es la única forma de vivir el territorio y de percibir los costes de la transplantación del espacio de vida. En el contexto en el que se desarrolla nuestra investigación no sólo es relevante el hecho de que, como ya se dijo, Galicia sea la región española con mayor índice de autoctonía; también lo es que haya sido un área tradicionalmente exportadora de emigración desde hace más de un siglo hasta hace escasamente una década.

Esto nos hizo considerar la posible influencia que tuviera sobre la disposición a la movilidad de los jóvenes la experiencia migratoria familiar registrada, por cuanto ésta podría ser vivida o revivida como una experiencia de movilidad asociada a la determinación y el control del futuro por parte de una voluntad 
emprendedora o como una experiencia de movilidad forzada asociada a una cierta voluntad resignada y fracasada o, al menos, no realizada en origen. En el primer caso, sería un estímulo positivo y tendería a ser imitada (la experiencia migratoria de generaciones anteriores llamaría a una mayor disposición a la movilidad por parte de la generación más joven). En el segundo, la experiencia migratoria familiar operaría como estímulo negativo que desalentaría la motivación a la movilidad por asociarla más con una incapacidad que con una capacidad.

Los datos obtenidos (Tabla 5) nos muestran que casi la mitad de la juventud gallega (49\%) tiene o ha tenido emigrantes entre sus hermanos, padres o abuelos. Sin embargo, la experiencia emigratoria familiar no sólo aparenta ser independiente de la predisposición, sino que incluso los resultados arrojan un índice ligeramente superior para los que carecen de esa experiencia ( 41,8 frente a $38,7)$. Este resultado se suma al registrado en el caso de la movilidad residencial personal. Ni en la vida propia ni en la memoria familiar, la movilidad registrada parece favorecer, pues, una mayor o menor tendencia a un cambio residencial futuro.

Pero, curiosamente, cuando la experiencia de movilidad tenida en cuenta no es la de la migración familiar, sino la de los viajes de los propios jóvenes (en cuanto que tales viajes no implican cambio residencial), obtenemos, sin embargo, una relación distinta (véase también Tabla 5). Cuanto mayor es la frecuencia de los viajes realizados y la distancia de los mismos, mayor es también la predisposición a cambiar de lugar de residencia en busca de un empleo.

Tabla 5.

Predisposición a la movilidad según experiencia viajera personal y experiencia de migración familiar

\begin{tabular}{l|lccc}
\hline \multicolumn{2}{l}{} & & $\begin{array}{c}\text { Porcentaje } \\
\text { respuestas }\end{array}$ & $\begin{array}{c}\text { Índice de } \\
\text { predisposición }\end{array}$ \\
\hline \multirow{3}{*}{ Viajes fuera de la región } & No & 30,0 & 33,4 \\
& 1 a 3 & 44,2 & 39,8 \\
& Más de 3 & 25,8 & 48,7 \\
\hline \multirow{3}{*}{ Viajes al extranjero } & No & 64,0 & 36,5 \\
& 1 a 3 & 28,6 & 45,1 \\
& Más de 3 & 7,4 & 52,5 \\
\hline \multirow{2}{*}{ Experiencia emigratoria familiar } & Si & 48,9 & 38,6 \\
& No & 51,1 & 41,7 \\
\hline
\end{tabular}

Fuente: Encuesta de Movilidad Espacial de la Juventud Gallega, 2003. 


\section{RIS}

Una perspectiva de la movilidad como la que aquí se desarrolla, atenta contra la forma en que el actor dota de sentido al espacio en que vive, y ha de fijar su atención necesariamente en la influencia de otro factor subjetivo de motilidad como es la identificación con el territorio. Al hacerlo nos encontramos con una relación parecida a la que encontramos al considerar el deseo de movilidad absoluta. Observamos, en primer lugar (Gráfico 7), que más de tres cuartas partes $(77,6 \%)$ de la juventud gallega manifiestan una identidad territorial localista, pues se identifican bien con Galicia (40,9\%), bien con su pueblo o ciudad (27\%), bien con su barrio $(9,7 \%)$. Sólo un escaso $7 \%$ se identifica con España o con el mundo, mientras que apenas un $2,3 \%$ se identifica como europeo. Así, si la disposición a la movilidad por empleo aumentaba a medida que lo hacía el alcance geográfico del deseo de vivir en otro sitio, podemos ver aquí que la motilidad laboral aumenta a medida que se deslocaliza la identificación territorial del entrevistado; es decir, cuanto mayor es el ámbito de referencia de la identificación sentida, mayor es su disposición a trasladarse en función de un empleo. La disposición a moverse de los que se identifican con Galicia o con España es parecida (44,5 y 45,1, respectivamente), pero mayor que la de los que se identifican con su pueblo o ciudad $(31,3)$ y menor que la de los pocos que se identifican con Europa $(54,2)$. Dado el mayor peso de los localistas en el conjunto de la muestra, sí parece haber una relación entre el tipo de identificación territorial de los jóvenes y su disposición a la movilidad.

\section{Gráfico 7.}

Predisposición a la movilidad según identificación territorial

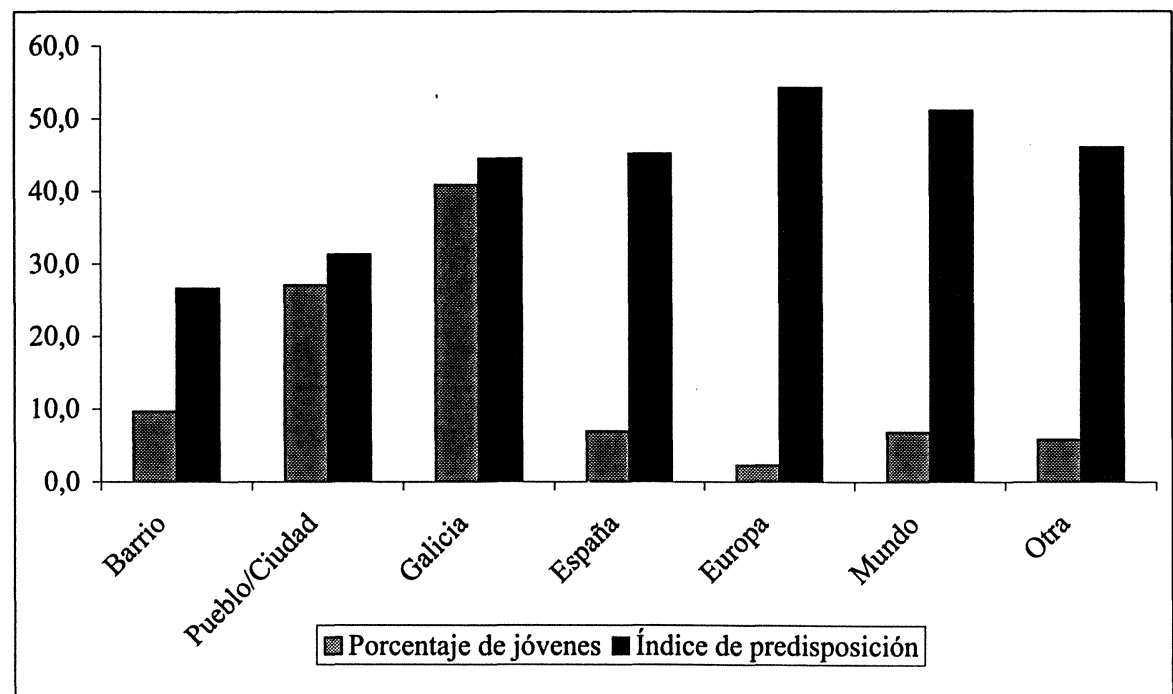

Fuente: Encuesta de Movilidad Espacial de la Juventud Gallega, 2003. 
Pero es lógico pensar que el ánimo a cambiar de residencia dependa no sólo del peso de la memoria viajera y la forma en que uno se identifica respecto al territorio (factores ligados a la vivencia del pasado y a su enraízamiento presente) sino también de la percepción del futuro. De ahí que otro factor subjetivo a considerar en la conformación del ánimo o predisposición a la movilidad de los jóvenes haya sido su optimismo, que aquí hemos medido por su valoración de la evolución de la situación económica y por su grado de acuerdo con la creencia de que cada vez va a haber más oportunidades para los jóvenes. En términos generales, la juventud gallega se muestra más optimista respecto a la situación económica general que respecto al aumento de sus oportunidades, pues un $41,5 \%$ de ellos cree que la situación económica mejorará, pero sólo una cuarta parte cree que aumentarán las oportunidades para ellos. No obstante, la predisposición a la movilidad de los que son más o menos optimistas en uno u otro sentido varía muy poco y lo hace de forma lineal sólo en el caso del optimismo abstracto (Gráfico 8).

Gráfico 8.

Predisposición a la movilidad según percepción de la evolución económica $y$ del incremento de oportunidades para los jóvenes

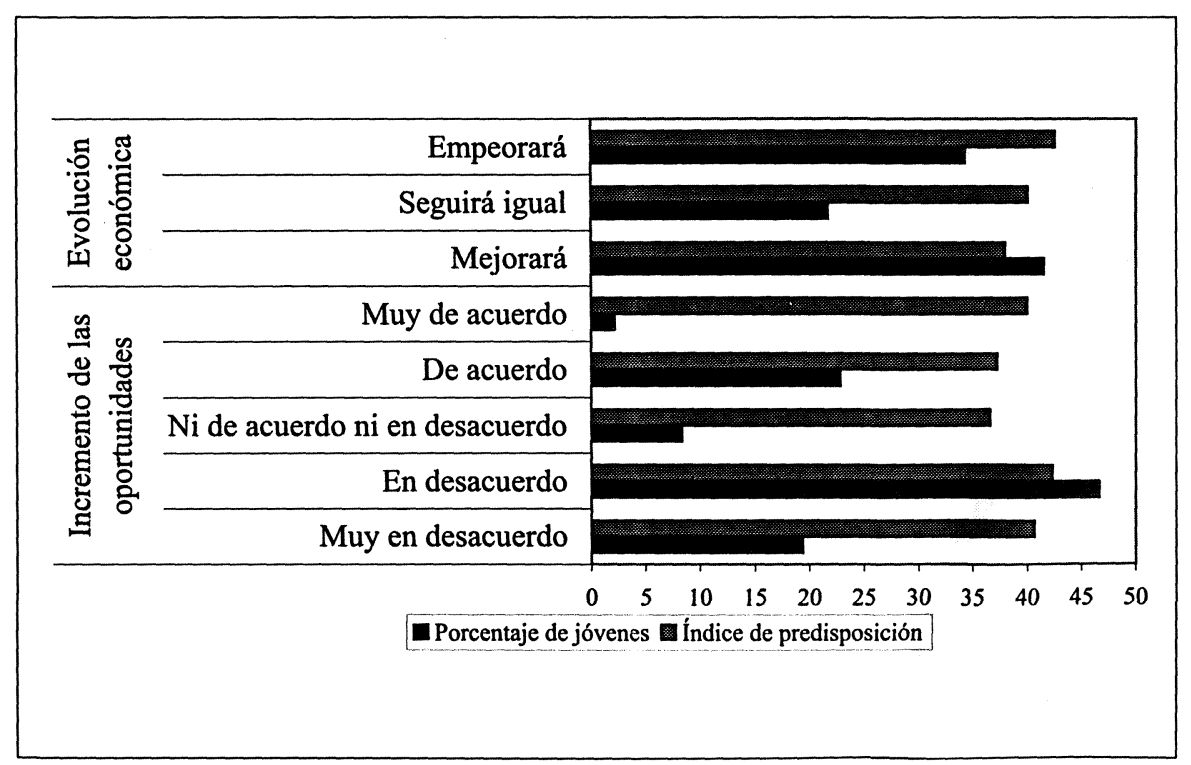

Fuente: Encuesta de Movilidad Espacial de la Juventud Gallega, 2003. 
RIS

REVISTA INTERNACIONAL DE SOCIOLOGÍA

$\mathrm{N}^{\circ}$ 42, SEPTIEMBRE-DICIEMBRE, 2005

MANUEL GARCÍA DOCAMPO y EDUARDO TERRÉN LALANA

Si medimos el optimismo por el grado de acuerdo con la idea de que las oportunidades para los jóvenes mejorarán, no encontramos una tendencia clara, pues, por ejemplo, los que se manifiestan muy de acuerdo con que dichas oportunidades aumentarán muestran una predisposición similar a la de los que albergan la creencia contraria (y similar, además, a la media del conjunto de los jóvenes que es 40,2). Parece, pues, que sólo cuando la perspectiva de futuro se formula en términos abstractos (situación económica en general) es el pesimismo más que el optimismo el que llama a la movilidad.

Claro que el mostrarse más o menos optimista puede estar también relacionado con la forma en que se crea que va a evolucionar aquello que se considera que es decisivo para que la trayectoria de uno sea más o menos exitosa. A este respecto hay que añadir que, de entre la tradicional batería de factores que se consideran claves para el éxito en la vida, nos hemos encontrado con que la disposición a la movilidad residencial por empleo es sólo ligeramente superior entre los que piensan que el empleo es muy o bastante importante en la consecución del éxito, a la de los que piensan que es poco o nada importante. En un sentido o en otro, son muy similares las diferencias que se registran en la consideración de otros factores, como la importancia percibida de los estudios, los contactos o el origen familiar en el éxito. No ocurre así, sin embargo, respecto a la suerte, pues quienes la consideran poco o nada importante muestran una disposición mucho mayor a la movilidad que los que creen que la suerte es un factor importante. Si la desconfianza hacia la suerte mueve a la movilidad, también debería hacerlo la confianza en el mérito personal como factor de éxito. Y, efectivamente, así ocurre, aunque la diferencia en la disposición a la movilidad entre los que confian mucho en sus méritos y los que no, es menor que la que se registra entre los que confian en la suerte y los que no.

\section{CONCLUSIONES}

En una sociedad caracterizada por la globalización y flexibilización de los mercados, por la expansión y creciente accesibilidad de las formas de transporte y comunicación, y por las políticas y modas que hacen de la movilidad un valor, la renuencia de los individuos ( $\mathrm{y}$, sobre todo, de los más jóvenes) a la movilidad y el atractivo de ésta puede parecer un fenómeno paradójico. Pero, tal y como se refleja en diversos informes y estudios revisados, el atractivo de la inmovilidad es un hecho tozudo. También lo confirma nuestro trabajo.

Nuestra investigación ha mostrado que, dentro de un perfil de escasa motilidad en términos generales, los que más claramente muestran una mayor predisposición a la movilidad residencial parecen ser los que tienen más predisposición a la movilidad absoluta, es decir, los que se sienten atraídos por el simple deseo de vivir en un sitio diferente y los que prefieren buscar nuevas experiencias a refu- 
giarse en la tranquilidad de los espacios y las relaciones ya conocidas. Quienes más frecuentemente y con mayor lejanía viajan, están sólo algo más predispuestos a aceptar un trabajo en un sitio diferente a aquel en que se reside. En este sentido, los programas que buscan favorecer la movilidad de los jóvenes (en especial de los estudiantes) con la idea de fomentar una mayor movilidad futura parecen bien encaminados si se da por bueno el objetivo de una mayor movilidad. Pero parece tratarse más bien de una experiencia personal o autónoma, pues, ni los que han residido a lo largo de sus vidas en diferentes municipios (se supone que fundamentalmente por traslados familiares) ni los que han tenido experiencia migratoria en sus familias muestran un nivel de predisposición significativamente mayor que los autóctonos o los que no tienen parientes cercanos en la emigración. Así es que no parece que el cambio residencial del pasado de las familias constituya una experiencia significativa en la motilidad de los jóvenes.

Existe un acuerdo prácticamente unánime en que la predisposición a la movilidad residencial es un elemento importante de la empleabilidad e inserción laboral de los jóvenes. En este sentido, nuestra investigación ha encontrado que, en términos generales, la predisposición de los jóvenes que estudian es sólo ligeramente superior a la de los que no estudian, y similar a la de los jóvenes parados (muy cercanas todas ellas, en cualquier caso, a la predisposición media general), que tienden a mostrarse más predispuestos a moverse si han trabajado antes que si buscan empleo por primera vez.

La transplantación del espacio de vida que implica la movilidad geográfica no parece, pues, algo de por sí atractivo para la mayoría de los jóvenes gallegos. La marcada preferencia por la inmovilidad residencial frente al cambio puede interpretarse en la misma línea de otras preferencias por formas de inserción laboral y social estables (sector público frente a privado, por cuenta ajena frente a autónomo, vivienda propia frente a alquilada), que sugieren una escasa disposición de los jóvenes a las formas de flexibilidad biográfica que favorecen la empleabilidad. Aunque la escasa motilidad laboral de la juventud parece muy poco sensible (o bastante invariante) al efecto de la mayoría de las variables consideradas, todo parece apuntar a que, más allá de las dificultades estructurales tradicionalmente esgrimidas (trabajo precario, vivienda cara), existen ciertos factores subjetivos 0 de índole cultural que tienen un enorme peso y que condicionan la motilidad en sentido negativo, haciendo atractiva la inmovilidad incluso en el caso de existir una motivación económica para ello.

La interpretación de los resultados de la encuesta presentados en este trabajo debe enmarcase, además, en el horizonte de problemas planteados en la sección introductoria y, muy especialmente, en la línea de investigación que busca profundizar en el estudio sociológico de la movilidad desde el punto de vista del actor. Así, debe observarse cómo al prestar atención al entorno interno de la "motilidad" hemos trabajado dentro del enfoque de la movilidad que Kaufmann (2002: 103) describe como el "abrir la caja oscura de la movilidad". Está implícita en este 
enfoque la crítica a la ignorancia del actor que se registra en la visión dominante de la movilidad, y creemos que la constatación de la baja predisposición a la movilidad de la juventud contribuye a subrayar la necesidad de distinguir los dos planos analíticos.

La proliferación de oportunidades de comunicación y transporte a disposición de los individuos se da efectivamente, y de hecho los viajes y las variaciones residenciales aumentan (incluso en Galicia, aunque con diferente sentido al de la emigración clásica). Pero el aumento de las posibilidades y la velocidad del traslado no conlleva automáticamente un incremento de la predisposición a la movilidad residencial de los individuos. Poder viajar más no implica querer vivir en otro sitio y el aumento de lo primero no resta atractivo al deseo de seguir viviendo donde se reside. La explicación de la coexistencia de estos dos fenómenos aparentemente divergentes puede radicar en el hecho de que, con el crecimiento de las opciones y la velocidad de movimiento, cambian también las formas de movilidad (viajar más vecès y más lejos, por ejemplo, tiene un menor coste y no lleva ya aparejada una variación residencial) y la experiencia misma de la movilidad, pues con dicho aumento se trastoca el sentido de distancia y cambia efectivamente la experiencia del espacio. Ésta sería una explicación acorde con la idea del sedentarismo nómada expuesta por Bericat (1994) como marco interpretativo de la movilidad contemporánea. Pero como complemento de la misma podría también considerarse - y ésta es la contribución de nuestra hipótesis-que la lógica de la predisposición a la movilidad residencial (la base motivacional que impulsa al movimiento) es muy sensible a factores de índole subjetivo o cultural que evolucionan independientemente de las condiciones externas de acceso a la movilidad.

\section{REFERENCIAS BIBLIOGRÁFICAS}

AGUSTIN, J.P. (1998), “Jeunes et mobilités urbaines”, Agora débats/jeneusses, n 13, pp. 7-13.

BAUMAN, Z. (2000), Liquid modernity, Cambridge, Polity Press.

BERICAT, E. (1994), Sociologia de la movilidad, Madrid, CIS.

CEC (6453/01), Comunicación de la Comisión Europea: "New European Labour Markets, Open to All, with Access for All" (Document 6453/01), remitida al Consejo Europeo de Estocolmo (marzo, 2001)

COURGEAU, D. (1988), Méthodes de mesure de la mobilité spatiale, París, Institute National d'études demographiques.

FISCHER, CL. S. (2002), "Ever-more rooted Americans", City and community, no 1(2), pp. 146157. 
FLAQUER, LL. (1997), El destino de la familia, Barcelona, Ariel.

FUNDACIÓN ENCUENTRO (2005), Informe España 2005, Madrid.

GARCÍA DOCAMPO, M. (2000), "El empleo de encuestas en la investigación sociológica del turismo en los lugares de destino", en Margarita Latiesa Rodríguez y Antón Álvarez Sousa (Comp.), El turismo en la sociedad contemporánea: diversificación, competitividad y desarrollo, Granada, Ed. Urbano, pp. 9-28.

GAVIRIA SABBAH, S. (2002) "Retener a la juventud o invitarla a abandonar la casa familiar Análisis de España y Francia”, Revista de Estudios de Juventud, 58, pp. 1-6.

IVIE/BANCAJA (2004), "Los jóvenes y la flexibilidad laboral”, Capital humano, 41 (www.ivie.es).

KAUFMAN, V. (2002), Rethinking mobility: contemporary sociology, Londres, Ashgate.

KRISTENSEN, S. (1998), "El apoyo a la movilidad internacional de los jóvenes", en A. Tassinopoulos, H. Werner y S. Kristenen, Movilidad y migración de la fuerza de trabajo en la UE: implicaciones especificas para los jóvenes, Informe CEDEFOP, Salónica.

LASH, S. y J. URRY (1998), Economias de signos y espacio, Buenos Aires, Amorrortu.

LEAL MALDONADO, J. (1997), "Emancipación y vivienda", en R. Verges (ed.), La edad de emancipación de los jóvenes, Barcelona.

LÉVY, J. (2000), "Les nouvaux espaces de la mobilité ", en M. Bonnet y D. Desjeux (eds.) Les territoires de la mobilité, pp. 155-170, París, PUF.

LÓPEZ PINTO, B. (1999), Comunicación presentada en la Conferencia regional sobre cooperación, (Trento, Italia) http://www.regione.taa.it/giunta/cooper/pinto/index_td.htm

MÓDENES CABRERIZO, J.A. (2000), "Movilidad residencial y dinámica familiar de los adultos jóvenes urbanos en los ochenta", VII Congreso de Población Española, "Juventud: la edad de las opciones", Madrid, abril.

(2004), "Movilidad residencial, trabajo y vivienda en Europa", Geocritica, UAB, VIII (159) accesible en www.ub.es/geocrit/sn/sn-159.htm.

ORFEUIL, J. P. (1994), “L'analyse de la mobilité”, Le Courier du CNRS, n 81, pp. 69-71.

PÉREZ DÍAZ, V. y J.C. RODRÍGUEZ (1998), "Jóvenes gallegos: disposiciones y comportamientos ante la educación y el mercado de trabajo", ASP Research Paper, $\mathrm{n}^{\circ} 24$.

SCHULER, M., B. LEPORI, V. KAUFMANN y D. JOYCE (1997), Eine integrative Sicht des Mobilität: Im Hinblick auf ein neues Paradigma des Mobilitätsforschung, Berna, Schweitzerischer Wissenchaftsrat.

TASSINOPOULOS, A. y H. WERNER (1998), "La movilidad y la migración de trabajadores en la UE", en A. Tassinopoulos, H. Werner y S. Kristenen, Movilidad y migración de la fuerza de trabajo en la UE: implicaciones especificas para los jóvenes, Informe CEDEFOP, Salónica. 
RIS

REVISTA INTERNACIONAL DE SOCIOLOGÍA

TFSM (2001), "Final report of the High Level Task Force on Skills and Mobility", http://europa. eu.int/comm/employment_social/general/index_en.htm, (14.12.2001).

URRY, J. (1999), “Mobile Cultures”, Department of Sociology, Lancaster University, Lancaster LA1 4YN, UK: http://www.comp.lancs.ac.uk/sociology/papers/Urry-Mobile-Cultures.pdf

VIART, J. (1994), La societé d'archipel ou les territories du village global, París, Editions de l'Aube. 